\title{
Gastric Changes Following Colchicine Therapy in Patients with FMF
}

Wael Ismail Al-Daraji · Riham M. W. Al-Mahmoud •

Mohammed Ilyas

Published online: 30 September 2009

(C) Springer Science+Business Media, LLC 2009

Retraction to: Dig Dis Sci (2008) 53:2079-2082

DOI 10.1007/s10620-007-0132-7

This article has been retracted.

The online version of the original article can be found under doi:10.1007/s10620-007-0132-7.

W. I. Al-Daraji $(\bowtie) \cdot$ M. Ilyas Department of Pathology, School of Molecular Medicine, University of Nottingham, Nottingham NG7 2UH, UK

e-mail: waldaraji@aol.com

R. M. W. Al-Mahmoud

Department of Medicine, Ain Shams University Hospital,

Cairo, Egypt 